\title{
LA INVENCIÓN DEL SÍ MISMO
}

Reseña

Patricio Rojas Navarro - Universidad Andrés Bello

Patricio Rojas Navarro

Psicólogo, Universidad Diego Portales Estudiante doctorado en Sociología en Goldsmiths, University of London Docente escuela de Psicología, Universidad Andrés Bello

Correspondencia:

Patricio Rojas Navarro

patricio.rojas.n@unab.cl 
¿Qué puede decirnos hoy en día un libro como "La Invención del Sí Mismo" de Nikolas Rose a quienes estamos interesados en el estudio crítico de la psicología y las llamadas 'disciplinas psi'? El propio autor nos da pistas al respecto cuando nos hace notar en el prefacio -que escribió especialmente para esta primera edición en castellano del texto- que se trata de un libro antiguo, pero que eso no lo priva de capacidad de operar con vigencia y de despertar nuestro interés. Esto último siempre y cuando su lectura actúe como punto de referencia, relevo y conexión para plantear nuevas preguntas sobre otros problemas, en otras temporalidades y geografías. Preguntas que nos ayuden a buscar, o más bien crear, nuevas formas de vivir. Rose propone entonces una lectura que tenga que ver más con la invención que con la exégesis.

“La Invención del Sí Mismo: Poder, Ética y Subjetivación” es, en cierto modo, un punto de llegada y a la vez un movimiento de pasaje en la obra de Rose. El remate de una trilogía de libros cuya publicación comienza en 1985 con The Psy Complex (Rose, 1985), continuando en 1989 con Governing the Soul (Rose, 1999a). Una tetralogía, en estricto rigor, si consideramos un misterioso volumen nunca publicado con estudios sobre la clínica Tavistock y que aparentemente sólo vio luz tardía y parcialmente en algunos ensayos del libro Governing the Present (Rose \& Miller, 2008).

Ateniéndonos a la trilogía efectivamente publicada, “La Invención del Sí Mismo” cerró en 1996 una serie de estudios publicados por Rose y que con el tiempo pasaron a ser reconocidos como parte clave y fundacional de un movimiento más amplio conocido como 'estudios de gubernamentalidad' (Dean, 2010). Bajo ese nombre se agruparon ampliamente investigaciones realizadas por diversos autores que -como suele subrayarse- se inspiraron en el trabajo de Michel Foucault en torno a la noción de gubernamentalidad (Burchell, Gordon \& Miller, 1991). Se trataba de trabajos creativos, impulsados por la obligación de ser algo infieles a un autor francés entonces 
publicado muy parcialmente y por lo mismo sólo conocido fragmentariamente. Eso apuró -con aciertos y limitaciones- una búsqueda teórico-empírica que rápidamente adquirió vuelo propio. Como señala Mitchell Dean (1996, p. 209), otro de los grandes nombres de dicho movimiento, la relación con la obra de Foucault era de apropiación de una caja de herramientas con la cual refrescar las posibilidades de la crítica. Los libros de Foucault operaban entonces más como "libros de experiencia" que como "libros de verdad".

Desde la década de 1980 en adelante los governmentality studies anglosajones fueron claves en la creación de un vocabulario teórico y de apuestas metodológicas que posibilitaron un ensamblaje afirmativo que permitió -y aún permite- diálogos entre campos disímiles como la psicología crítica, geografía, sociología, ciencia política, economía, filosofía, etc. El hilo conductor que los reúne, siempre parcialmente, es la forma en que -siguiendo a Foucault (2006)- proponen entender que las razones de gobierno o artes de conducir la conducta implican formas de ejercicio del poder que establecen una continuidad entre el gobierno de las poblaciones, las familias, los individuos, y las relaciones que estos establecen consigo mismos y con los demás. Esto abrió un abanico de cuestionamientos fértiles para despertar pasiones y curiosidades en campos muchas veces distantes.

Dentro los estudios de gubernamentalidad, el trabajo de Rose se planteó en términos de una historia o genealogía del presente, buscando prolongar y recrear la propuesta foucaultiana de emprender una ontología crítica de nosotros mismos. Así, el sociólogo inglés enfatizó el análisis del papel que esa serie de prácticas, discursos y materialidades -que siguiendo a Jacques Donzelot (Rose, 2016) llamó “complejo psi”- ha interpretado en la constitución las formas, siempre entrecruzadas y nunca inocentes, en que nos pensamos, juzgamos y actuamos sobre nosotros mismos y los demás (Rose, 2019, p. 267). 
¿Qué clase de criaturas creemos que somos? ¿Cómo llegamos a entendernos de ese modo y con qué consecuencias? Son preguntas conductoras que Rose hace y a las que retorna una y otra vez. Las despliega de forma hábil y convincente a través del relieve sinuoso que componen los capítulos heterogéneos -en origen y temática- que se compilaron en "La Invención del Sí Mismo". Vale la pena reseñar parte del trayecto que antecedió a este volumen, impecablemente traducido en esta primera edición en castellano: en "The Psychological Complex" Rose (1985) parece interesado en rastrear los orígenes de la creación del "sujeto moral de la psicología" mediante las coordinaciones y fricciones no entre filosofía y fisiología, como suele contarse de forma autogratificante cierta historia de la psicología, sino entre ciencia ampliamente entendida y la administración de los individuos. Es en ese encuentro donde la psicología, según la ahora bien conocida propuesta de Rose, no fue tanto capaz de generar una normatividad propia, sino que más bien terminó por adquirirla a partir normatividades “ajenas” y propias de las exigencias y técnicas gubernamentales de gestión de la población, de la estadística, y de las diversas demandas y propuestas de medición de las capacidades de los individuos con que las democracias occidentales del siglo XX -particularmente la de Inglaterra- intentaban organizar, coordinar, regular y conducir a la población. Posteriormente, en "Governing the Soul” (Rose, 1999a), la pregunta respecto de cómo nos constituimos como 'sí mismos' lleva a Rose a realzar el problema de la libertad en una acepción progresivamente diseminada y encarnada, tanto social como políticamente, a lo largo del siglo XX británico: toda persona se entiende como un sí mismo subjetivo y libre, siendo el ejercicio de esa libertad lo que las define en su relación consigo mismas y con los demás. Es ese particular ejercicio de la libertad, además, el que articula a esas subjetividades y sujetos con la maraña de mecanismos, tácticas y programas propios de las gubernamentalidades liberales avanzadas. “Obligados a ser libres”, es quizás la frase más conocida de esta propuesta de Rose y que titula 
una de las partes más conocidas del libro, que sintetiza la incitación seductora ejercida por las artes de gobierno liberal avanzado a la hora de conducir a poblaciones, individuos y cuerpos. En este texto, el análisis del papel insidioso que han desempeñado las técnicas y vocabularios de la psicología y las psicoterapias en posibilitar y reforzar ese nexo entre cierta forma de subjetivación y las artes de gobernar neoliberal pasa a primer plano.

¿Qué pasa con las preguntas de Rose al llegar a “La Invención del Sí Mismo”? Se puede aventurar que encuentran un espacio de afianzamiento y, al mismo tiempo, cierta agitación cuyas razones hoy, más de veinte años después de su publicación, sólo pueden conjeturarse. En lo capítulos 1 y 2 del libro (“¿Cómo debería hacerse la historia del sí mismo?” y “Una historia crítica de la psicología”) el autor presenta algo que aparece como la consolidación de un plan de trabajo ya aceitado para orientar la realización de una genealogía de las subjetividades y subjetivaciones contemporáneas y el rol que la psicología -y la diseminación social de sus saberes, tecnologías, prácticas, formas de inteligibilidad y propuestas éticas y de valoración de nosotros mismos y de los demás- ha jugado en su capitalización por parte de las formas contemporáneas de gubernamentalidad neoliberal . En otros capítulos, por ejemplo, el número 7 (“Gobernando individuos empresariales"), se prolongan los ejemplares estudios de caso de Rose. ¿Qué tienen en común una línea telefónica de autoayuda promocionada en los diarios del Reino Unido a fines de los años 80s, las "lógicas del neoliberalismo", la "cultura empresarial", y el "sí mismo" de los individuos de las democracias liberales occidentales? La respuesta, desarrollada durante todo el capítulo, permitirá al autor mostrar que no se trata de elementos ajenos entre sí, sino de una suerte de coordinación productiva casi coreográfica, donde la gubernamentalidad neoliberal implica un ejercicio del poder que no trabaja contra la subjetividad, sino que a través de ella y tomándola como objeto, blanco y recurso fundamental para la producción de ciertas formas de 
(auto)regulación y para una constitución conveniente de lo que a individuos y sociedades aparece como posible, legítimo, aceptable o deseable.

Pero "La Invención del Sí Mismo" contiene también momentos donde la seguridad y consolidación del autor parecen dar paso a ejercicios de búsqueda, tanteo y apertura. El capítulo 8 del volumen ("Ensamblando-nos") es un ejemplo. Ahí el trabajo de Rose se vuelve más bien especulativo. Uso esta palabra en el mejor de los sentidos, es decir, cuando especular es detener el ritmo de la marcha, no apresurase en anticipar y demostrar, sino abrirse a crear nuevos apetitos y riesgos para un pensamiento en marcha (Stengers, 2011). Así, en "Ensamblando-nos" el texto parece mostrar los signos del encuentro transformador con otras formas de teoría social e investigación empírica que llegan a levantar nuevas preguntas y problemas. Esto no sólo por la destacada presencia de Gilles Deleuze y Félix Guattari como autores con cuyas propuestas y conceptos Rose trabaja arduamente para articular una renovada posición propia, si no por las huellas de otras preocupaciones que vienen a remover en algo las preguntas habituales del autor.

Quizás la noción clave para seguir este rastro en el texto esto sea la noción de ensamblaje, palabra que titula el capítulo y que podemos entender también, con los mismos Deleuze y Guattari (2015), como agenciamiento. Pensar la subjetivación como un ensamblaje-agenciamiento, ¿cuál es la novedad de ello? En una de las menciones del término, Deleuze dice que en los agenciamientos se encuentran mescolanzas: de cuerpos, cosas, enunciados, modos de expresión, regímenes de signos y, sobre todo, una reunión contingente, flujo de heterogeneidades tanto "naturales" como "artificiales" (Deleuze, 2008). La subjetivación como ensamblaje nos lleva de ese modo a recorrer territorio familiar en el sentido de prolongar el gesto crítico de no entenderla como un proceso comandado por un sujeto individual, una interioridad de la conciencia, o una supuesta esencia universal estable. Pero también arroja al texto de Rose a otro campo de 
problemas. Pensar la subjetivación como ensamblaje-agenciamiento permite ensayar expansiones para la caja de herramientas con que nos preguntamos qué clase de criaturas somos. Con la idea de ensamblaje la subjetivación pasa a ser algo a indagar en detalle y sin generalizaciones apresuradas -tendencia que ha generado críticas importantes a los estudios de gubernamentalidad anglosajones en tanto pareciera que las gubernamentalidades generarían correlativamente y en masa formas de subjetividad y sujetos. Las subjetividades y subjetivaciones como ensamblajes implican cambiar de rumbo, conllevan acompañar a éstas en su detalle, en sus trayectorias y flujos heterogéneos, entre coherencias e incoherencias que no respetan distinciones tajantes entre psíquico y corporal, entre humano y no humano, entre individual y colectivo. En este sentido, en el capítulo 8 parecen resonar los ecos de la creciente influencia en los años 90s de autoras y autores como Rosi Braidotti, Elizabeth Grosz, Michel Callon, Bruno Latour o Donna Haraway, invitándonos a rastrear en estos ensamblajes-agenciamientos las formas de agencia que emergen con (o pese a) ellos, y las consecuencias que tienen para la disputa cotidiana -vital y dinámicarespecto de qué consideramos nuestro mundo común. No se trata de una pregunta inocente: si Donna Haraway (1991) se célebremente se preguntaba con la sangre de quién se crearon nuestros ojos, vale la pena preguntarnos también con la sangre de qué y quiénes se sostienen nuestras subjetividades-ensamblaje, nuestros si mismos - psicológicos o no.

En resumen, “La Invención del Sí Mismo” sigue siendo un libro vigente, sobre todo cuando lo abordamos desde la invitación de su autor a tomarlo como punto de partida para lanzar nuevas formas de indagación crítica que examinen nuestras formas de vivir y relacionarnos. Dicha invitación queda extendida particularmente, por cierto, a aquellos profesionales y estudiosos de la psicología que hoy intentan seguir analizando las prácticas y saberes con que, con plena vigencia, psicólogas y psicólogos siguen posicionándose y siendo ubicados como "expertos de la 
subjetividad" autorizados a transformar nuestras preguntas existenciales en preguntas técnicas. La tarea sigue siendo urgente: después de todo, más de 20 años después, la descripción que Rose hace del sí mismo neoliberal -cuyos vocabularios e inteligibilidades, sus posibilidades de alivio y sufrimiento, sus criterios de normalidad y anormalidad, sus nociones de lo adecuado o inadecuado y sus anhelos respecto de cómo ha de vivirse una vida bien vivida, han emergido en parte importante desde las disciplinas psi-, sigue siendo escalofriantemente vigente:

El sí mismo consiste en emerger como un ser subjetivo, en aspirar a la autonomía, en perseguir la realización personal en la vida terrenal, en interpretar su realidad y su destino como un asunto de responsabilidad individual, en encontrar el significado de la existencia en la modelación de la vida a través de la elección (Rose, 2019)

Luego de "La Invención del Sí Mismo" Rose siguió otros caminos. Extendió el examen detallado del problema político de la libertad y el gobierno de los individuos en Powers of Freedom (Rose, 1999b), y desde ahí su obra redirigió las coordenadas de la pregunta respecto de qué clase de criaturas somos hacia las ciencias de la vida, las neurociencias y la psiquiatría biológica cuyos avances científicos y socio-culturales nos han llevado a devenir, tensa y muchas veces paradojalmente, como sí mismos psicológicos y, a la vez, como sí mismos neuroquímicos e individuos somáticos (Rose, 2006, 2018; Rose \& Abi-Rached, 2013). La psicología quedó, para Rose, atrás. Hoy son otros las invitadas e invitados a tomar la posta y re-examinar el rol que "lo psi” juega y puede llegar a jugar en la mantención, intensificación o recreación de nuestros presentes y futuros.

\section{Referencias}

Burchell, G., Gordon, C., \& Miller, P. (Eds.). (1991). The Foucault Effect: Studies in Governmentality. Chicago: University of Chicago Press. 
Dean, M. (1996). Foucault, government and the enfolding of authority. En A. Barry, T. Osborne, \& N. Rose (Eds.), Foucault and Political Reason: Liberalism, Neo-Liberalism, and Rationalities of Government (pp. 209-229). Chicago: University of Chicago Press.

Dean, M. M. (Ed.). (2010). Governmentality: Power and Rule in Modern Society (Second Edition). London: Sage.

Deleuze, G. (2008). Dos regímenes de locos: Textos y entrevistas (1975-1995). Valencia: PreTextos.

Deleuze, G., \& Guattari, F. (2015). Mil Mesetas: Capitalismo y Esquizofrenia. Valencia: PreTextos.

Foucault, M. (2006). Seguridad, Territorio, Población: Curso en el Collége de France (1977-1978). Buenos Aires: Fondo de Cultura Económica.

Haraway, D. (1991). Simians, Cyborgs and Women: The Reinvention of Nature (2nd edition). London: Free Association Books.

Rose, N. (1985). The Psychological Complex: Psychology, Politics and Society in England, 18691939. London: Routledge Kegan \& Paul.

Rose, N. (1999a). Governing the Soul: The Shaping of the Private Self (2 edition). London: Free Association Books.

Rose, N. (1999b). Powers of Freedom: Reframing Political Thought. Cambridge: Cambridge University Press.

Rose, N. (2006). The Politics of Life Itself: Biomedicine, Power, and Subjectivity in the TwentyFirst Century. Princeton and Oxford: Princeton University Press.

Rose, N. (2016). Governing the soul - a quarter of a century on. Self \& Society, 44(4), 431-433. https://doi.org/10.1080/03060497.2015.1053219 
Rose, N. (2018). Our Psychiatric Future: The Politics of Mental Health. Cambridge ; Medford, MA: Polity Press.

Rose, N. (2019). La Invención del Sí Mismo: Poder. Ética y Subjetivación (S. Vetö, N. Bornhauser, \& F. Valenzuela, Trads.). Santiago de Chile: Pólvora.

Rose, N., \& Abi-Rached, J. M. (2013). Neuro: The New Brain Sciences and the Management of the Mind. Princeton, N.J: Princeton University Press.

Rose, N., \& Miller, P. (2008). Governing the Present: Administering Economic, Social and Personal Life. Cambridge: Polity Press.

Stengers, I. (2011). Cosmopolitics II. Minneapolis: University of Minnesota Press.

Recepción: 25 de septiembre de 2019

Última Revisión: 20 de noviembre de 2019

Aceptación Final: 9 de diciembre 2019 